\title{
Disseminated fibrin thromboembolism among neonates dying more than 48 hours after birth
}

\author{
J. F. BOYD \\ From the Brownlee Laboratory, University Department of Infectious Diseases, Ruchill Hospital, Glasgow, and \\ the Department of Pathology, Western Infirmary, Glasgow
}

SYNOPSIS Of 119 neonates dying after 48 hours of life, $19(16 \%)$ showed disseminated fibrin thromboembolism, a histological condition that is very similar to one form of maternal hypofibrinogenaemia. The incidence is nearly five times that among stillbirths and neonates dying within 48 hours of birth.

Most of the mothers had a normal pregnancy, labour, and puerperium. One twin may show the condition while the other survives. It is suggested that the affected infants have either no fibrinolytic mechanism, a defective one, or one which for some unaccountable reason was not brought into action. The antecedent plasma fibrinogen level is likely to have been high in some cases, but a fatal outcome can ensue with normal or low levels. The process was considered to be totally responsible for death in six cases $(5 \%)$ of the series. Renal tubular hyaline droplets apparently rich in haemoglobin were only encountered in one infant (no. 4) who died from massive bilateral adrenal haemorrhage.

In the later part of the neonatal period, the process is liable to be indistinguishable clinically from secondary thrombotic processes, which occurred with almost the same incidence in the present series $(14(12 \%)$ of 119 cases $)$.

This article continues a series of reports about disseminated fibrin thromboembolism (Boyd, 1958, 1965,1966 , and 1967). The purpose has been to determine if any stillbirth or neonatal death could result from a process similar to that occurring in one variety of fatal maternal hypofibrinogenaemia. In this variety, placental or decidual thromboplastin is believed to enter the maternal circulation to cause intravascular fibrin thrombosis and embolism selectively involving the plasma and lodging particularly in the capillaries of the pulmonary circulation (Johnstone and McCallum, 1956). Since the untreated state may be rapidly fatal in the mother, I created an artificial division in my study of neonatal deaths, by considering that neonates dying primarily from this condition would do so within $\mathbf{4 8}$ hours of birth, whereas neonates who died after this selected time would not show this feature.

Disseminated fibrin thromboembolism is easily missed in haematoxylin and eosin-stained sections, but is more easily noted after staining by one of the methods for showing fibrin. Lieb's (1948) phos- photungstic acid haematoxylin (PTAH) was employed since it was a method which had given faithful service locally and could be adapted readily for staining sections in bulk.

In this article, findings are recorded and illustrated if they have not been covered adequately in previous articles. The series is recorded elsewhere in detail (Boyd, 1960).

\section{MATERIALS AND METHODS}

In a series of 676 necropsies on stillbirths and neonates, there were 119 on neonates dying more than 48 hours after birth. A fifth of these cases were studied retrospectively, and thus a complete histological record was not always available. The remaining four-fifths was a prospective study, and full histological records were nearly always made. Both haematoxylin and eosin- and PTAH-stained sections were studied.

\section{THE PRESENT SERIES}

Among the 119 cases, 33 patients $(28 \%)$ were found 
to have antemortem thrombi histologically. Of these, $19(16 \%)$ were considered to be examples of disseminated fibrin thromboembolism from features detailed in the earlier papers, and therefore to be similar to certain fatal cases of maternal hypofibrinogenaemia (Table). This article is concerned with these 19 patients, five of whom $(4 \%)$ showed no other lesion, if the ensuing haemorrhagic manifestations are accepted as a part of the syndrome. These five patients, whose ages range from 51 hours to 10 days, could be combined therefore with eight neonates dying within 48 hours of birth with the same lesion (Boyd, 1967). Consequently the division which I had created had been set too low. The other 14 patients showed evidence of infectionrespiratory in eight cases, meningeal in one case, alimentary in three cases, and septicaemic in two cases. In these 14 cases, the possibility was considered that the vascular lesions were the consequences of infection, and was assessed as unlikely from the criteria detailed in my earlier articles.

On the other hand, the vascular thrombi noted in the 14 remaining cases were believed to be the con $\frac{0}{\bar{c}}$ sequences of infection (pulmonary in five cases alimentary in four cases, and umbilical in one case) 0 as well as being associated with congenital conts ditions in two cases and surgical conditions in two $\overrightarrow{0}$ In these patients, the thrombi were mixed in com position, were arising from vessel walls being implicated by the infective process, and from sluggish blood flow since the fibrin strands laye haphazardly in relation to the direction of blood flow. None of these patients will be considered? further, except to mention that their ages ranged from 3 to 28 days, overlapping therefore the series under discussion. There will be difficulty in the future, both clinically and in the laboratory, when efforts are made to distinguish 'primary' disseminate

T A B L E

FINDINGS IN 19 NEONATES LIVING FOR MORE THAN 48 HOURS AND SHOWING DISSEMINATED FIBRIN THROMBOEMBOLISM

\begin{tabular}{|c|c|c|c|c|c|c|c|c|c|c|c|c|}
\hline \multirow{2}{*}{$\begin{array}{l}\text { Case } \\
\text { No. }\end{array}$} & \multicolumn{4}{|l|}{ Maternal State ${ }^{1}$} & \multirow{2}{*}{$\begin{array}{l}\text { Length of } \\
\text { Gestation } \\
(w k)\end{array}$} & \multirow{2}{*}{$\begin{array}{l}\text { State of } \\
\text { Placenta }^{1}\end{array}$} & \multirow{2}{*}{$\begin{array}{l}\text { Infants' } \\
\text { Survival } \\
\text { Time } \\
\text { (days) }\end{array}$} & \multicolumn{5}{|c|}{ Organs Showing Fibrin Thromboembolism ${ }^{2}$} \\
\hline & Age (yr) Parity & Antepartum & $\begin{array}{l}\text { Intra- } \\
\text { partum }\end{array}$ & $\begin{array}{l}\text { Post- } \\
\text { partum }\end{array}$ & & & & Lungs & Spleen & Liver & Adrenals & $\begin{array}{l}\text { Central } \\
\text { Nervous } \\
\text { System }\end{array}$ \\
\hline
\end{tabular}

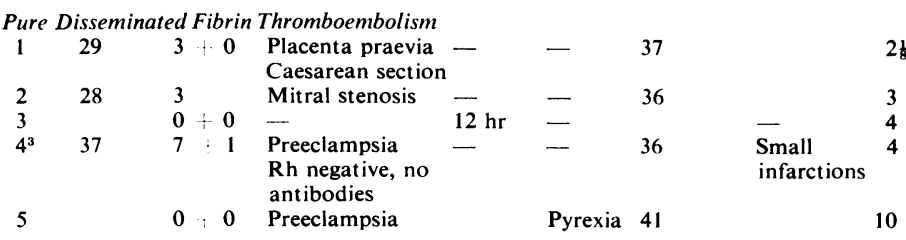

Associated Respiratory Tract Infection

$10^{3} \quad 36$

$11^{3} \quad 28$

$12^{3}$
13

Associated Meningitis

$14^{3} \quad 30 \quad 1+0$

Twins, premature -

labour

Associated Gastrointestinal Infection

$\begin{array}{lllll}15^{3} & & 6 & \text { - } & - \\ 16 & 40 & 3 & \text { Antepartum }\end{array}$

17

0

$18 \quad$ Rh negative with - -

19

0

antibodies

$\begin{array}{ll}- & - \\ - & - \\ \text { Breech } & - \\ - & - \\ - & -\end{array}$

38

40

29

Numerous 11

infarctions

12

$-$

13

15

Binovular; 6

infarctions

40

Total

(1)

System

${ }^{1}$ Full information was not always available if delivery occurred at home or at a distant hospital.

${ }^{2}+$ and - indicate presence and absence of thromboemboli; a blank indicates that no histological examination was made.

${ }^{8}$ Cases reported in text. 
fibrin thromboembolism from thrombosis occurring secondarily. In practical terms, however, if the use of fibrinolytic agents becomes a standard therapeutic measure the distinction may not be important.

Cases 1 and 3 (Table) which were cases 8 and 4 respectively in my earlier series (Boyd, 1965) are not reported here. Seven other cases are reported in varying detail below.

CASE 4 The mother was admitted at 36 weeks with mild preeclamptic toxaemia; Rhesus negative but no antibodies. The membranes were ruptured artificially, and labour lasted for 10 hours. Small infarctions were found in the placenta. The puerperium was normal. The infant, a girl, weighed $2,900 \mathrm{~g}\left(6 \frac{1}{2} \mathrm{lb}\right)$, and was pale and limp, but showed no evidence of haemolytic disease of the newborn. She improved the next day but vomited and refused feeds two days later, when oxytetracycline was given. She collapsed suddenly and died aged 4 days. The heel blood fibrinogen level at 12 hours was $243 \mathrm{mg}$ per $100 \mathrm{ml}$ (normal value, unpublished results). Postmortem examination showed mild icterus, blood-stained ascites, and massive bilateral adrenal haemorrhages. The right adrenal gland was totally destroyed, but two-thirds of the left adrenal gland was intact. Histological examination of both glands showed extensive fibrin deposition, its pattern resembling that of the adrenal sinusoids destroyed in most areas by the massive haemorrhages (Fig. 1). The lesions can be more accurately described as bilateral haemorrhagic infarctions. Fibrin thromboemboli were absent from the other major organs, including the placenta.

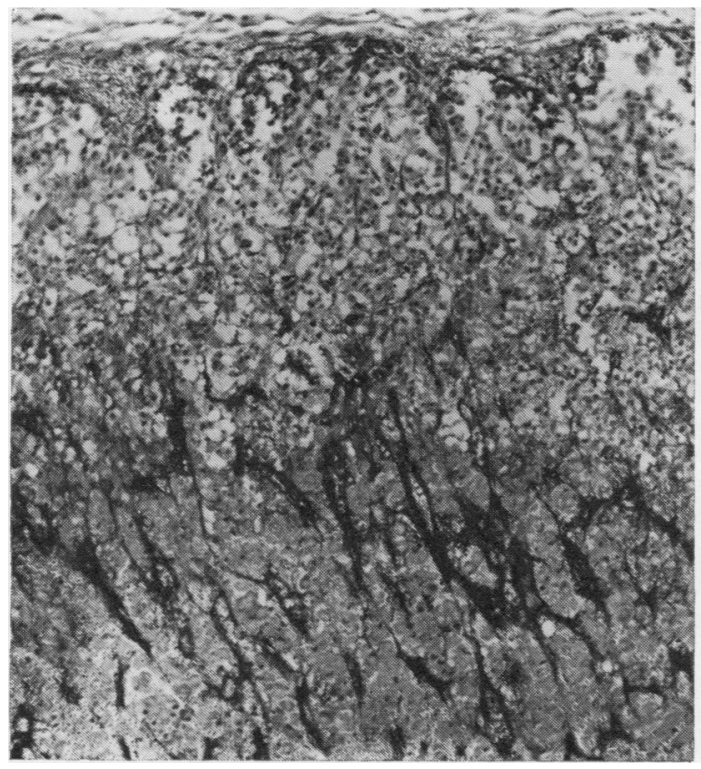

FIG. 1. Case 4. Left adrenal gland with sparing of the definitive cortex and confluent sinusoidal fibrin thromboembolism with haemorrhage and necrosis in the deeper (foetal) cortex. PTAH $\times 95$.
CASE 7 The infant was born at home, oesophageal atresia was diagnosed. and she was admitted to hospital but died from $S$. aureus bronchopneumonia aged $3 \frac{1}{2}$ days. Histological examination showed extensive hepatic sinusoidal fibrin thromboembolism accompanied by fatty change in the periphery of the lobules and necrosis of the centres (Fig. 2). The spleen showed extensive sinusoidal fibrin thromboembolism, and the unaffected sinusoids showed compensatory dilatation.

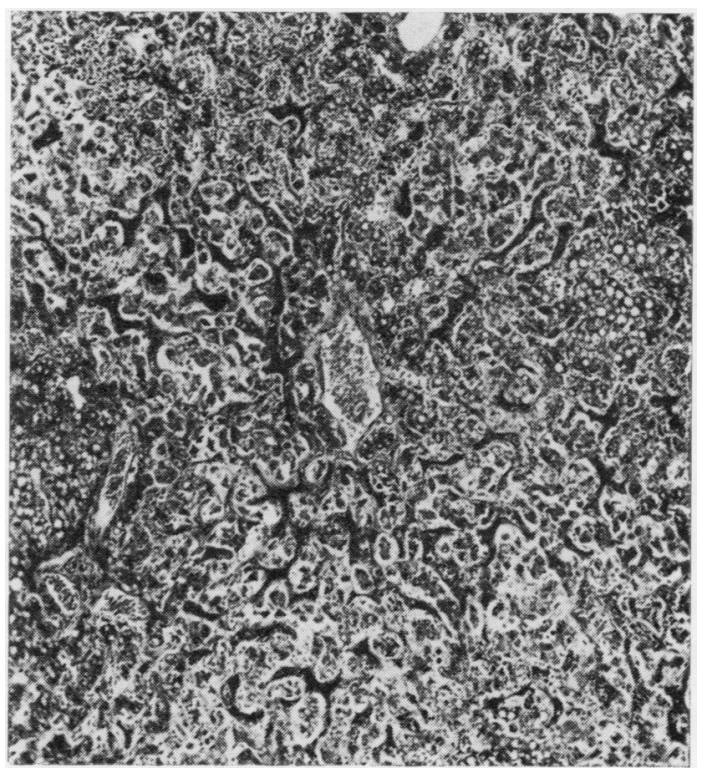

FIG. 2. Case 7. Widespread confluent hepatic sinusoidal fibrin thromboembolism causing mid- and centrilobular fatty change and necrosis $(P T A H \times 95)$.

CASE 10 The mother went into premature labour at 37 weeks, with a breech delivery. The puerperium was normal. The placenta bore numerous large white infarctions. The infant at birth weighed $1,100 \mathrm{~g}\left(2 \frac{1}{2} \mathrm{lb}\right)$, his colour was poor, he did not respond to treatment, and died at 11 days. Postmortem examination showed patchy bronchopneumonia, and histological examination showed fibrin thromboemboli only in the pars distalis of the pituitary gland (Fig. 3). Fibrin thromboemboli were not present in any other organ studied.

In my entire series of 676 necropsies, this case is the one to show the greatest pituitary involvement.

CASE 11 The mother had vaginal bleeding at the 14th week and mixed accidental haemorrhage at the 29 th week when labour started; the puerperium was satisfactory. The infant, $1,100 \mathrm{~g}\left(2 \frac{1}{2} \mathrm{lb}\right)$, was well at first, but became cyanotic at 12 hours and adrenal cortical extract and sulphamerazine were given. Her condition was unchanged for five days, but she deteriorated on the tenth day, when sulphamerazine was stopped and chloramphenicol started. Grey cyanosis was seen over the next two days, and the 


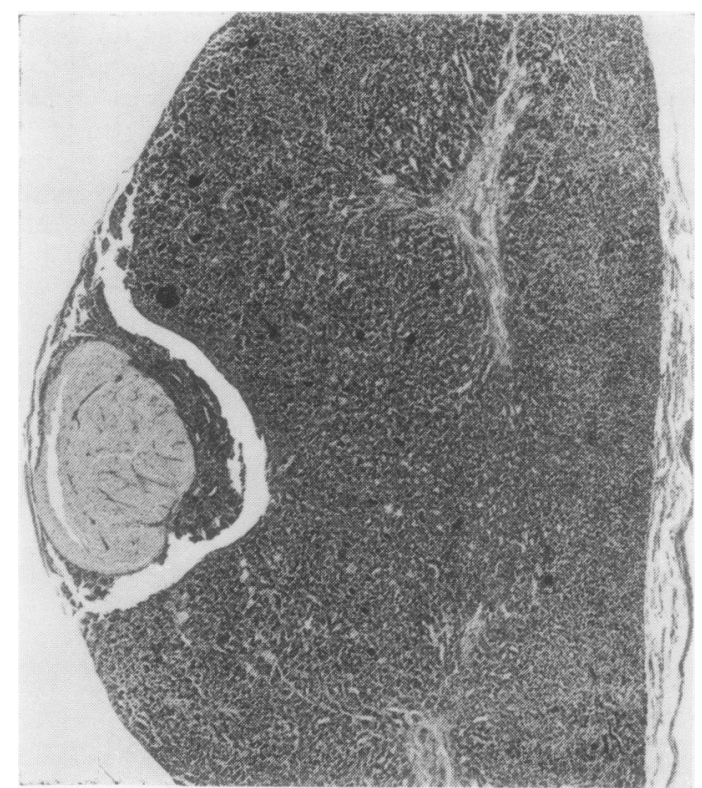

FIG. 3. Case 10. Pituitary gland showing widespread sinusoidal fibrin thromboemboli most of which are not attenuated $(P T A H \times 17)$.

baby died on the 12th day. The postmortem examination showed suppurative bronchopneumonia and a haemorrhage near the superior horn of the left lateral ventricle. Histological examination confirmed these features, and, of three brain blocks, one showed a microscopic cerebral softening with compound granular corpuscles and a glial response. Alongside, there was a vessel with pure fibrin thromboembolism which was proven by serial sections to be occluding one branch of a bifurcation (Fig. 4).

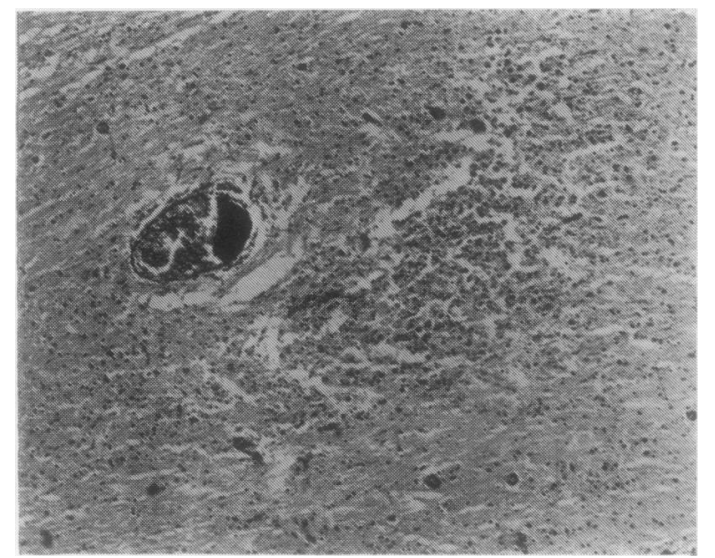

FIG. 4. Case 11. Pure fibrin thromboembolus lodged at the bifurcation of a cerebral vessel (proven by serial sections, and the carina at this level has two layers of endothelium). Well established cerebral infarction alongside $($ PTAH $\times 45)$.
CASE 12 Pregnancy was normal and vertex delivery was. spontaneous at 42 weeks. The placenta and puerperium $\vec{s}$ were normal. The infant, birth weight $2,700 \mathrm{~g}(6 \mathrm{lb})$, was dismissed home on the sixth day, and was well until the 10th day, when vomiting and five soft green motions caused admission to hospital. Stools were negative for pathogenic bacteria, and tetracycline was given. The baby's condition deteriorated and the anterior fontanelle乡 became tense. The antibiotic was changed to novobiocinand erythromycin. A chest radiograph showed left pleuraP effusion, and paracentesis yielded pus from which $S$. aureus (phage type 80 ) was cultured. The infant died on the 13th day.

Postmortem examination showed bilateral empyemato with consolidation of both lower lobes and the right middle lobe from which $S$. aureus (phage type 80) was cultured. There was also extensive intracranial durab sinus thrombosis with subdural haemorrhages and bilateral intraventricular haemorrhages. (This infant was one of those described in the report of Timbury, Wilson, Hutchison, and Govan in 1958.) Histology confirmed these findings. In uninfected areas of the lungs, however there were severe pulmonary haemorrhages, and pures retracted fibrin thromboemboli were lodged in the capillaries and venules (Fig. 5) of some of these areas. In addition, the kidneys showed focal fibrin thrombosiso of the arcuate veins (Fig. 6), retracted to one side of the vessel wall and almost completely endothelialized whereas in the more major tributaries of the renal vein the process converted to laminated mixed thrombuss which showed no evidence of retraction or endothelialio zation (Fig. 7). The pulmonary lesions were not conveno tional emboli from the dural sinuses or from the rena veins, and indeed the lesions affected capillaries and venules rather than large arteries. The other major organs were not affected.

CASE 14 The patient was admitted at 31 weeks in pre mature labour with twins. The first twin, $1,700 \mathrm{~g}\left(3 \frac{3}{4} \mathrm{lb}\right)$ was delivered by assisted breech delivery, and the second:$1,800 \mathrm{~g}$ (4lb), by spontaneous vertex delivery. The second twin survived. The first twin was active and was placed in a humid incubator with $40 \%$ oxygen. Oedema lasted two days, and was followed by jaundice for two days, and then by irritability, rolling eyes, bizarre limb movements, and facial grimacing. Chloral hydrate failed to control these, and death followed on the sixth day.

Postmortem examination showed confluent pulmonary haemorrhages in the lower lobes, pyogenic meningiti? localized to the left parietal, temporal, and occipitall lobes and posterior fossa. Smears showed numerous Gram-negative bacteria but there was no growth on culture. Dissection showed haemorrhagic softening (2.\& $\mathrm{cm})$ in the parieto-occipital area, deep to the meningitis while an independent, wedge-shaped area of confluen $\bar{D}$ petechial haemorrhages affected the right parietal area? There was no skull fracture. Numerous fibrin thrombo=0 emboli were seen only in the haemorrhagic areas of braip (Fig. 8). The liver was also affected. The source of menin $\mathbb{8}$ gitis remained undetermined, there being no otitis mediag umbilical sepsis, or bronchopneumonia, and the haemorr hagic softenings showed no evidence of infection. 


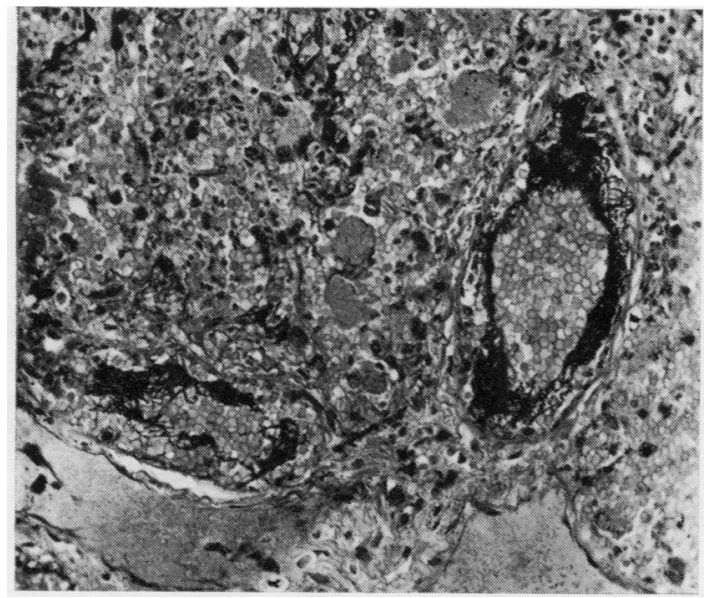

FIG. 5 .

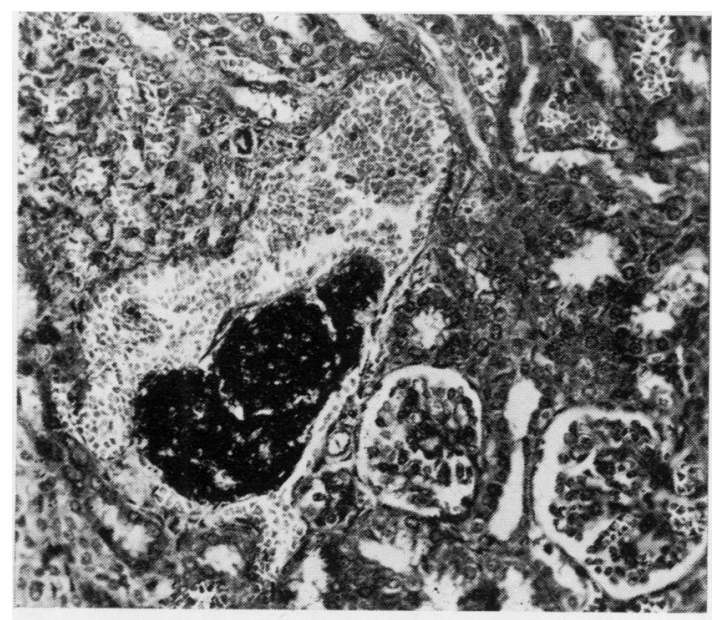

FIG. 6.

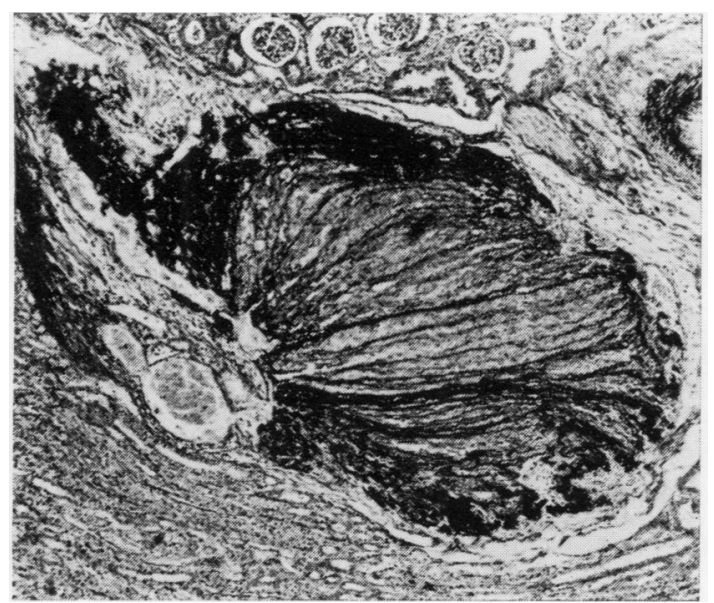

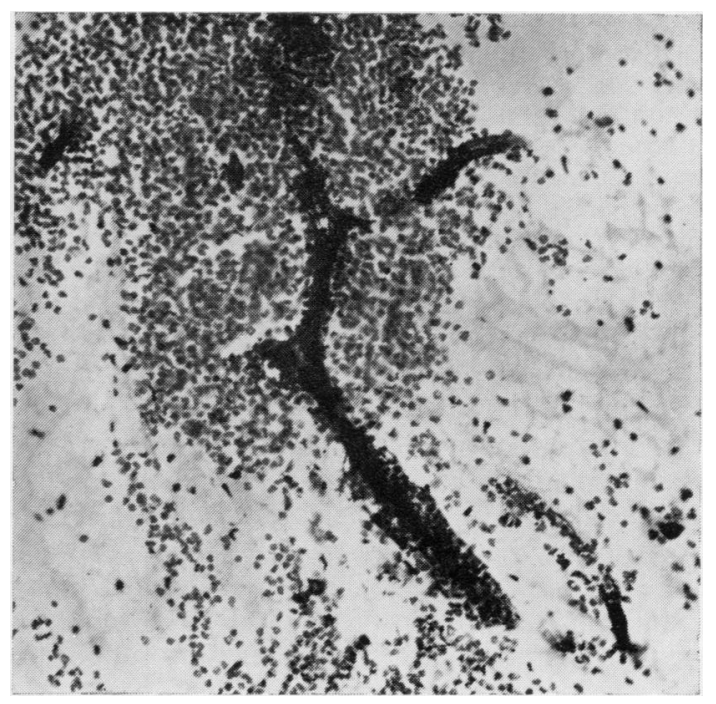

FIG. 8.

FIG. 5. Case 12. Fibrin thromboembolism in pulmonary venules, retracted against intimal surface $(P T A H \times 170)$.

FIG. 6. Case 12. Fibrin thrombus in an arcuate vein with contour of the lumen, and showing retraction and complete covering by endothelium $(P T A H \times 170)$.

FIG. 7. Case 12. More recent mixed laminated thrombus in larger renal vein of same kidney, that is, a migrating thrombosis. Pure fibrin thrombus present in tributary $(P T A H \times 45)$.

FIG. 8. Case 14. Fibrin thromboembolism affecting a branching cerebral vessel whose walls are now destroyed. Superficially, corpuscles have become enmeshed by fibrin strands. There is much surrounding haemorrhage (PTAH $\times 170)$.

F1G. 7 . 
CASE 15 The infant, born postmaturely at 43 weeks after a normal pregnancy (birth weight $3,700 \mathrm{~g}, 8+\mathrm{lb}$ ), went home on the sixth day. Four days later, he passed six loose green stools and refused all feeds. He was admitted to hospital, no pathogens were isolated, and he died on the 16th day.

Postmortem examination showed dehydration, absence of the thyroid gland, bilateral bronchopneumonia, and mucosal ulceration of the small and large intestines. Retracted pure fibrin thromboemboli were present in arterioles in the lower oesophagus (Fig. 9), in arterioles and capillaries related to a gastric erosion (Fig. 10), and in arterioles, capillaries, and venules of ulcerated areas in the small intestine (Fig. 11). Extracellular Grampositive cocci were seen on the surface of the last lesions.

This case is the only one in my series to show such lesions affecting the alimentary tract in spite of studying several infants with gastroenteritis of known and unknown aetiologies. The findings suggest that the plasma in which clotting had been initiated was channelled anteriorly in the aorta to enter the coeliac and superior mesenteric arteries. No lesions, however, were encountered in the liver or spleen. Although scanty smaller ulcers affected the descending and sigmoid colons, that is, in the territory supplied by the inferior mesenteric artery, it is unfortunate that none of these particular lesions was studied histologically. It is not certain therefore that the distal colonic lesions were similar to the others. The distribution of pure fibrin thromboemboli in arteries, capillaries, and veins in this case is similar to that found in other organs in this series of publications.

\section{DISCUSSION}

Data about the maternal state during pregnancy are deficient in several instances, but this is due to deliveries occurring at home and it is therefore fairly safe to assume that the mothers had had normal pregnancies. Only three mothers had antepartum haemorrhages; none was sufficiently severe to be investigated for hypofibrinogenaemia. Only two had mild preeclampsia. Thus there is no consistent maternal state to suggest an aetiological factor and this finding is similar to those in my earlier publications (Boyd, 1965, 1966, and 1967).

This series includes two sets of twins. One of each set died. The surviving member either did not experience fibrin thromboembolism, or it was mild in degree, or the lesions affected a non-vital area of the body.

The incidence in different organs in the three series (Boyd, 1966, 1967, and this one) appears to reflect certain genuine differences, because a fairly standardized procedure was adopted through the entire prospective study. For example, the relative lack of involvement of the kidneys is striking in alf three series (two cases in 36 reported cases) in $\overrightarrow{\vec{s}}$ contrast to lung involvement (10 cases, all of whicht were neonates, in 36) and adrenal involvement (nine cases in 36). This sparing of the kidneys probablyen reflects the relatively poor blood supply, apart fromb that required for growth and development, since the placenta performs most of the foetus's excretorys functions during intrauterine existence, but othero publications (Zuelzer, Kurnetz, and Charles, 1951; Sanerkin and Evans, 1965) show that the kidneys. of stillbirths and neonates may be involved from time to time. There is, however, a certain irrationality about the standard procedure of selecting tissue blocks $N$ for histological study. For example, three, four or five blocks from brain (335 g) are scarcely com- $-\mathrm{W}$ parable with two blocks of liver $(80 \mathrm{~g})$ or with threeo blocks from lungs weighing $30 \mathrm{~g}$ (five during the perinatal mortality survey (Butler and Bonham, $z$ 1963).) Modification of this type of study, however? to map the distribution of fibrin thromboemboli in a very large series of stillbirths and neonatal deathso might yield information about the normal distribution of blood to the various organs (Barcroft, 1946\% Dawes, 1958).

The present series suggests that these infants' fibrinolytic mechanism was either lacking or deficient or was never mobilized. Assuming that the thromboembolic process was initiated close to theo time of birth (and the stillbirth series showed that it could be initiated in the foetus up to four weeks before the onset of labour), the affected neonates 3 survived up to 28 days and there was no histological evidence to suggest that the lesions encounteredo were undergoing fibrinolysis. Indeed the illustration for case 12 shows endothelialization taking place, aso was seen in case 18 which is not illustrated. This series of histological reports adds weight to the haema tological study of Merskey, Johnson, Kleiner, and Wohl (1967) which noted two main varieties of the defibrination syndrome-the acute which lasts from? hours to days, and the subacute form from days to $>$ weeks, and a third mild chronic form which they? did not encounter personally. Jacobsen (1966) has N shown that low proteolytic capacity of the plasma may be genetically determined, but there is noo evidence to suggest that any patient in my series $\omega$ belongs to this condition.

This series adds weight to the suggestion made ino my earlier reports that a high plasma fibrinogen $\mathbb{0}$ level is an antecedent requirement for a fatal out-? come in some cases, but it would seem from others? in the present series that the process can be fatal even with normal or low plasma fibrinogen levels. $\stackrel{?}{\oplus}$ For example, case 10 showed only a few lesions in $\mathbb{Q}$ the pituitary (Fig. 3), and case 11 only a few cerebrato 


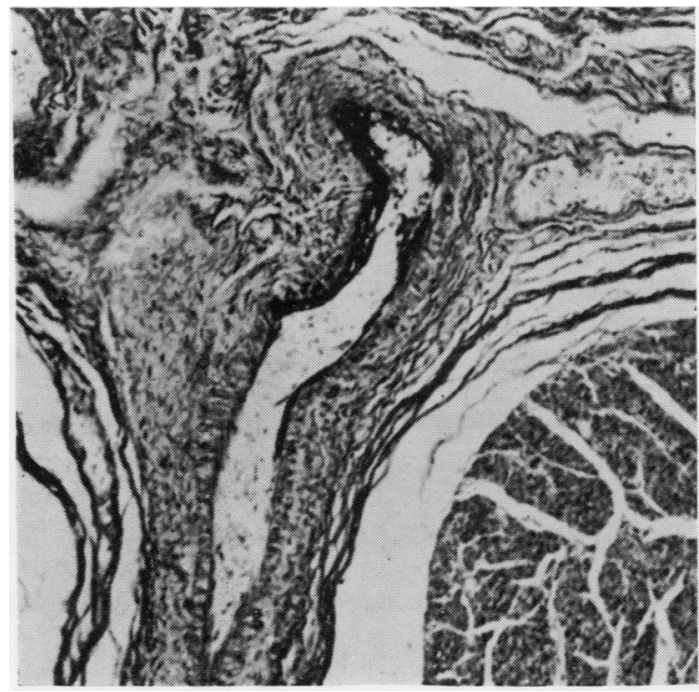

FIG. 9.

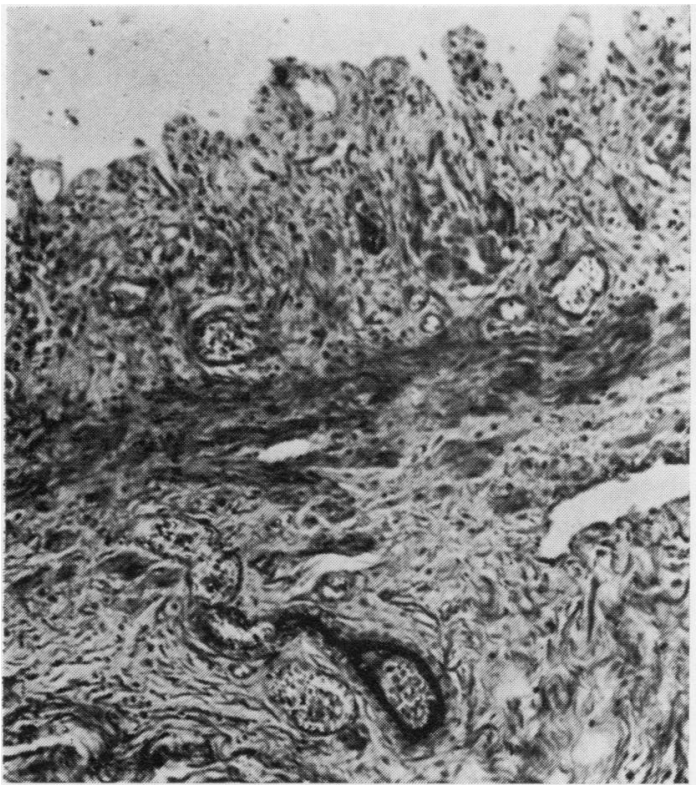

FIG. 10 .

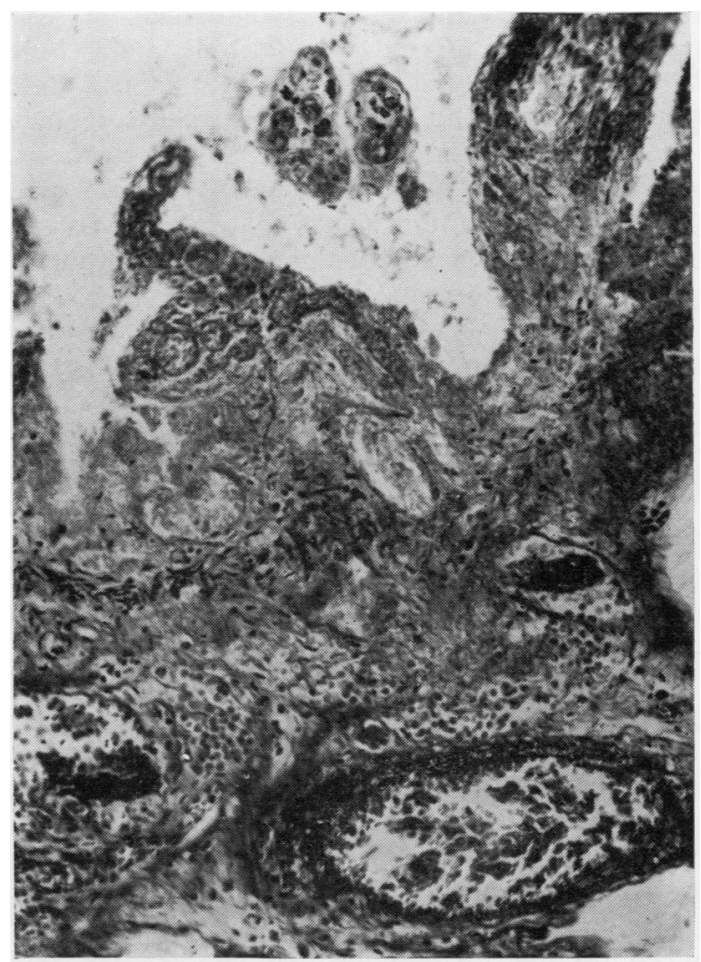

FIG. 11.

FIG. 9. Case 15. Penetrating arteriole of lower end of oesophagus showing laminated fibrin thrombus on its intimal surface $(P T A H \times 110)$.

FIG. 10. Case 15. Stomach wall showing laminated arteriolar fibrin thromboembolism (black) in the submucosa, and patchy capillary fibrin thromboembolism in the mucosa $(P T A H \times 110)$.

FIG. 11. Case 15. Small intestine showing laminated fibrin thromboembolism in arteriole (below), axial fibrin thromboemboli in several villous capillaries (to the left and above), and axial venous fibrin thromboemboli $(P T A H \times 145)$. 
lesions (Fig. 4). The outcome can be fatal, provided that the few fibrin thromboemboli lodge at strategic points, or death may ensue from the consequent haemorrhagic phenomena which are unrelated to the antecedent fibrinogen level. Further, a small lesion in a non-vital region, for example, a segment of lung, may predispose to fatal superadded infection with or without consequent septicaemia; there are five such deaths in this series.

Survival after a thromboembolic incident may be followed by secondary haemoglobinaemia and haemoglobinuria (Bywaters and Dible, 1942; Bull, Rubenberg, Dacie, and Brain, 1967; Rubenberg, Bull, Regoeczi, Dacie, and Brain, 1967; Regoeczi, Rubenberg, and Brain, 1967; Brain, Bull, Dacie, Regoeczi, and Rubenberg, 1968), although Wehinger and Künzer (1968) quote evidence that haemolysis can precede the thromboembolic process. In 17 of the 19 cases of fibrin thromboemboli sections of kidney were available and these were scrutinized to determine the presence or absence of haemoglobin tubule casts, haemoglobin droplets in renal tubule cells (Bryant, 1967; Rosen, Hano, and Barry, 1968), and haemosiderin pigment in the renal tubule cells. The kidneys of the 'positive' stillbirth cases and 48-hour neonates were studied simultaneously (Boyd, 1966, 1967). No case showed the conventional homogeneous strongly eosinophilic or brown haemoglobin tubule cast staining positively by the peroxidase or leucopatent blue methods (Pearse, 1961), or with kiton fast red (Lendrum, 1957). However, three patients in the present series showed renal tubular hyaline droplets but in only one (case 4) did the droplets stain similarly to the red blood corpuscles in the same section by the methods listed above. The droplets also stained deeply blue-black with PTAH, but this last finding is not specific for haemoglobin (nor indeed are any of the other methods), since PTAH stains mitochondria in a similar fashion. In the three kidneys incidentally there were other prominent blue-black and/or red-brown 'hyaline droplets', but these droplets were clearly negative by the methods for haemoglobin, and were Gram-negative and not fuchsinophilic. Haemosiderin was not present in any case. Clearly time is required for the apparently haemoglobin-rich hyaline droplets to develop in relation to an episode of fibrin thromboembolism. On the other hand, these features can be evanescent and in other instances the renal architecture may have returned to normal before the foetus or neonate died. Thirdly, it is possible that most haemoglobin in the plasma was conserved, or, if it was excreted it went by the placental route rather than by the infant's renal tract.

Only two cases in this series had intravenous infusions. Case 17 had Sonne dysentery and required saline to combat dehydration. Case 18 had erythroblastosis foetalis and required one exchange trans- $\overrightarrow{\vec{F}}$ fusion. The fibrin thromboemboli in both cases arenot considered to be the result of intravenous $\frac{C}{0}$ therapy or umbilical vein catheterization (Scott, 1965; Sanerkin, Edwards, and Jacobs, 1966). The $\widehat{\varnothing}$ thrombi and emboli resulting from these procedures are found in the large vessels, they are of mixed ${ }^{\infty}$ composition, and do not affect the arterioles $\vec{O}$ and capillaries and sinusoids or venules as fibrin $\overrightarrow{\vec{H}}$ thromboembolism classically does.

While the process may be confused in the early응 part of the neonatal period with haemorrhagic disease of the newborn (and vitamin $K$ preparations $N$ were given to cases $2,6,9,10,11$, and 18 of the present series), in the later part of the neonatal period the process is liable to be indistinguishable clinically응 from secondary thrombotic processes (Gray, Ackerman, and Fraser, 1968). A battery of blood clotting $Z$ tests is unlikely to help in distinguishing the one? type from the other. It is more likely however, that $\frac{\Phi}{3}$ the platelet count will be depressed in the more severe examples of secondary thrombosis such as cerebral sinus and renal vein thrombosis, whereas $\vec{\varnothing}$ the platelet count should remain normal in pure 6 examples of disseminated fibrin thromboembolism 0 since the initiator of this process is considered to be placental (tissue) thromboplastin. Unfortunately platelets may become implicated secondarily in disseminated fibrin thromboemboli, as shown earlier $\stackrel{\square}{\square}$ (Boyd, 1967) and in case 1 of this article, and this $\underset{F}{\not}$ will lead to confusion in interpretation of the results $\frac{0}{3}$ (Merskey et al, 1967). Brodsky, Meyer, Kahn, and Ross (1968) have also studied this problem with a series of tests.

In conclusion, an effort was made to assess the importance of the lesions described in causing death. The process (or its haemorrhagic sequelae) is believed to have been wholly responsible for death in cases $\delta$ $3,4,8,12,13$, and 16 (5\% of 119 patients), partly responsible in cases $1,2,9,11,14,15,17,18$, and 19 윽 ( $7 \frac{1}{2} \%$ of 119 patients), and was an incidental finding $>$ in the remainder (cases $5,6,7$, and 10). However, this series presents the pathologist with numerous $N$ difficulties which were not so complex in the earlier series (Boyd, 1966, 1967), and unmerited importance 0 may be attached to any of these, thus leading to a $\vec{\omega}$ false assessment.

I am very grateful to Professor D. F. Cappell, Dr A. D. T. Govan, Dr A. M. MacDonald, and Dr R. A. Rankin for $\square$ providing me with many facilities for carrying out this $\overline{0}$ work, and to the obstetricians and paediatricians for $\stackrel{\mathbb{D}}{\mathbb{D}}$ permission to extract the relevant case records. Mr N. L. $\stackrel{\odot}{\Phi}$ Russell, Mr D. Johnstone, Miss M. Malcolm, Mr W. Marshall, and Mr A. Ireland carried out the technicalo 
aspects of this work. The photomicrographs were taken by $\mathrm{Mr}$ G. Kerr.

\section{REFERENCES}

Barcroft, J. (1946). Researches on Prenatal Life, vol. I Blackwell, Oxford.

Boyd, J. F. (1958). Surg. Gynec. Obstet., 106, 176.

- (1960). Antemortem thrombosis in stillbirths, neonates, infants and children, with particular reference to disseminated fibrin thrombo-embolism. D.M. Thesis, Glasgow University.

(1965). J. Path. Bact., 90, 53.

- (1966). J. Obstet. Gynaec. Brit. Cwlth, 73, 629.

- (1967). Arch. Dis. Childh., 42, 401.

Brain, M. C., Bull, B. S., Dacie, J. V., Regoeczi, E., and Rubenberg, M. L. (1968). Lancet, $1,90$.

Brodsky, I., Meyer, A. N., Kahn, S. B., and Ross, E. M. (1968). Amer. J. clin. Path., 50, 211.

Bryant, S. J. (1967). J. clin. Path., $20,854$.

Bull, B. S., Rubenberg, M. L., Dacie, J. V., and Brain, M. C. (1967). Lancet, 2, 1123.

Butler, N. R., and Bonham, D. G. (1963). Perinatal Mortality. The First Report of the 1958 British Perinatal Mortality Survey. Livingstone, Edinburgh and London.

Bywaters, E. G. L., and Dible, J. H. (1942). J. Path. Bact., 54, 111.
Dawes, G. (1958). Changes in the circulation at birth and the effects of asphyxia. In Recent Advances in Paediatrics, edited by $D$. Gairdner, 2nd ed. Churchill, London.

Gray, O. P., Ackerman, A., and Fraser, A. J. (1968). Lancet, 1, 545.

Jacobsen, C. D. (1966). Scand. J. clin. Lab. Invest., 18, 359.

Johnstone, J. M., and McCallum, H. M. (1956). Scot. med. J., 1, 360.

Lendrum, A. C. (1957). Progress Report to Caledonian Branch of the Association of Clinical Pathologists.

Lieb, E. (1948). Arch. Path., 45, 559.

Merskey, C., Johnson, A. J., Kleiner, G. J., and Wohl, H. (1967). Brit. J. Haemat., 13, 528.

Pearse, A. G. E. (1961). Histochemistry. Theoretical and Applied, 2nd ed., pp. 517, 652, 903 and 904. Churchill, London.

Regoeczi, E., Rubenberg, M. L., and Brain, M. C. (1967). Lancet, 1,601 .

Rosen, S., Hano, J. E., and Barry, K. G. (1968). Arch. Path., 85, 36.

Rubenberg, M. L., Bull, B. S., Regoeczi, E., Dacie, J. V., and Brain, M. C. (1967). Lancet, 2, 1121.

Sanerkin, N. G., Edwards, P., and Jacobs, J. (1966). J. Path. Bact., $91,569$.

- , and Evans, D. M. D. (1965). Ibid., 90, 269.

Scott, J. M. (1965). Arch. Dis. Childh., 40, 426.

Timbury, M. C., Wilson, T. S., Hutchison, J. G. P., and Govan, A. D. T. (1958). Lancet, 2, 1081.

Wehinger, H., and Künzer, W. (1968). Ibid., 2, 1085.

Zuelzer, W. W., Kurnetz, R., and Charles, S. (1951). Amer. J. Dis. Childh., 81, 2.

\section{Reports and Bulletins prepared by the Association of Clinical Biochemists}

The following reports and bulletins are published by the Association of Clinical Biochemists. They may be obtained from The Administrative Office, Association of Clinical Biochemists, 7 Warwick Court, Holborn, London, W.C.1. The prices include postage, but airmail will be charged extra. Overseas readers should remit by British Postal or Money Drder. If this is not possible, the equivalent of $10 \mathrm{~s}$. is the minimum amount that can be accepted.

\section{SCIENTIFIC REPORTS}

8 Automatic Dispensing Pipettes. An assessment of 35 commercial instruments. 1967. P. M. G. BROUGHTON, A. H. GOWENLOCK, G. M. WIDDOWSON, and K. A. AHLQUIST. 10s.

\section{TECHNICAL BULLETINS}

9 Determination of Urea by AutoAnalyzer. November 1966. RUTH M. HASLAM. 2s. 6d.

10 Filter Fluorimeters. A comparative list of 14 instruments. March 1967. HANNELORE BRAUNSBERG. (Reissued in response to demand. Text still valuable, list now out of date.) $5 \mathrm{~s}$.

11 Determination of Serum Albumin by AutoAnalyzer using Bromocresol Green. October 1967. B. E. NORTHAM and G. M. WIDDOWson. 2s. 6d.
12 Control Solutions for Clinical Biochemistry. February 1968. P. M. G. BROUGHTON. 2s. 6d.

13 An Assessment of the Technicon Type II Sampler Unit. March 1968. B. C. GRAY and G. K. MCGOWAN. 1s. 6d.

14 Atomic Absorption Spectroscopy. An Outline of its Principles and a Guide to the Selection of Instruments. May 1968. J. B. DAWSON and P. M. G. BROUGHTON. 4s.

15 A Guide to Automatic Pipettes (2nd edition). June 1968. P. M. G. BROUGHTON. 5s.

16 A Guide to Automation in Clinical Chemistry. May 1969. P. M. G. BROUGHTON 12s. 6d. (\$1.50).

17 Flame Photometers (2nd edition). 1969. P. WILDING. 12s. 6d. (\$1.50). 